\title{
DEVELOPING GIS-BASED DISASTER MANAGEMENT SYSTEM FOR LOCAL AUTHORITY - CASE STUDY IN MALAYSIA
}

\author{
${ }^{1}$ Alias Abdul Rahman, ${ }^{1}$ Hairi Karim, ${ }^{1}$ Ivin A. Musliman, ${ }^{1}$ Bernad Siew, ${ }^{1}$ Hanis Rashidan, \\ ${ }^{2}$ Sharif Idros, ${ }^{2} \mathrm{M}$. Al-Hafiz Azman, and ${ }^{2} \mathrm{M}$. Fadzli Abdullah \\ ${ }^{1}$ Department of Geoinformation, Universiti Teknologi Malaysia, Malaysia. \\ ${ }^{2}$ Pengerang Local Authority, Johor, Malaysia.
}

KEY WORDS: GIS, Map publishing, Disaster management

\begin{abstract}
:
This paper describes the development of geospatial-based disaster management system for an agency at regional level. Important aspects of the system such as spatial data, geospatial database, interface and specific modules for the disaster management system form major discussions of this paper. The Pengerang Disaster Management System (PDMS) is being developed for a local authority in one of the Malaysian states who's been given a task to monitor the surrounding environmental aspects. The local authority manages one of the largest oil and gas refinery plant in South East Asia region in collaboration with national oil company, PETRONAS. The PDMS, is a one-stop centre (dashboard) for managing the operations with other agencies or stakeholders such as police, marine, army, medical team, fire and rescue units. We anticipate many aspects of disaster management could trigger from this pilot project and thus provide some interesting ideas for a local authority in managing man-made disaster such as fire, other oil and gas related incidents. Some features of the developed system such as online map publishing services, data flow and other geospatial analysis during the event will be discussed in this paper. Near-future work and a big picture of the disaster management approach (with an emphasis to oil and gas incident and scenario) also will be highlighted.
\end{abstract}

\section{INTRODUCTION}

\subsection{Introduction}

Recently, we have seen more and more natural or man-made disasters happened and getting chaotic such as Hurricane Katrina in United States, Haiti, Japan, China and other disasters in Australia. Managing this kind of disasters is not easy and involves many parties or stakeholders. Many systems have been developed for disaster management where each provides different scopes of works and helps. It is not exaggerating to say that there is no system able to solve various level of disaster in Malaysia. However, the related agencies attempt to develop such system in the country such as National Agency for Disaster Management (NaDMA) as reported by NaDMA (2017) and Razak (2017).

A GIS-based system could be utilised to manage small scale disaster. This paper describes a system development for such small scale rather than national scale - natural or man-made. Section 2 describes GIS datasets. System development in Section 3 and finally the conclusion in Section 4.

\section{GIS DATA}

\subsection{Existing Data and Conversion}

The existing (provided) datasets is based on Kota Tinggi District Municipality (Majlis Daerah Kota Tinggi) archives and Figure 1 shows the boundary and area covered within PBT Pengerang jurisdiction. Below is the list of available datasets:

\section{- Environment}

- Economy

- $\quad$ Planning concept

- Transportation

\section{- Administrative}

- Social and Utility

Unfortunately, most of the provided digital data needs to undergo some updates and corrections - e.g. editing (see Figure 2). The original data is in MapInfo format (*.tab) which then converted into shapefile format (*.shp) using FME Quick Translator. The converted data in *.shp format were then verified for a defined coordinate system transformation (Cassini Johor) and geometry/attribute validation.

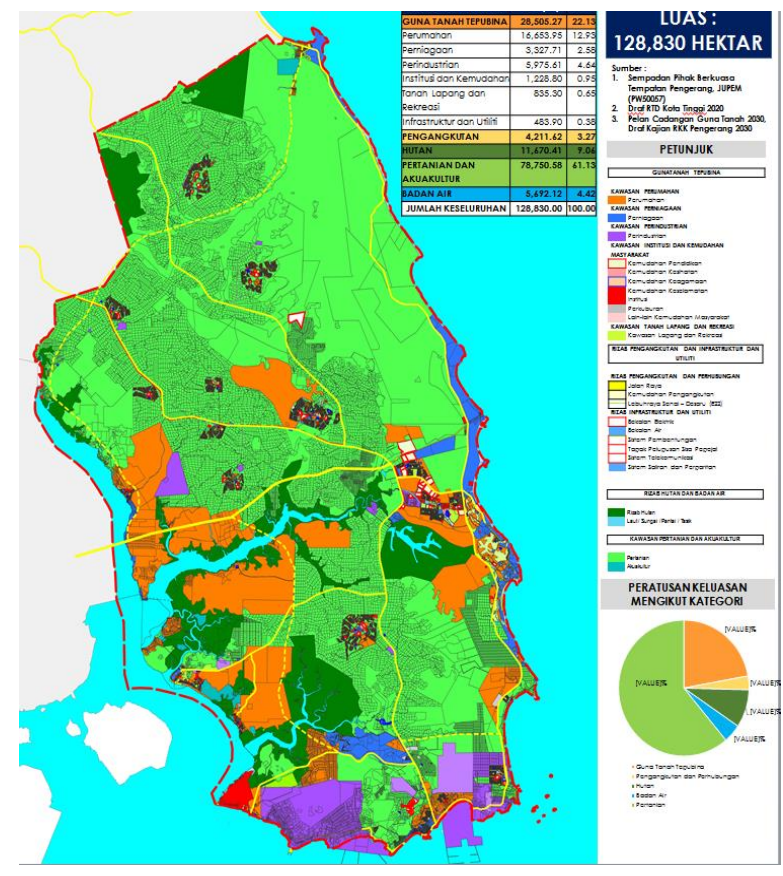


Figure 1: Regional planning map as initial reference given for PBT Pengerang jurisdiction area $(128,830 \mathrm{Ha})$

\subsection{Data Validation}

The provided GIS datasets are not up-to-date, contains slightly geometry error (e.g. shifted positions as in Figure 2, 3 and 4), and lack of attributes information.

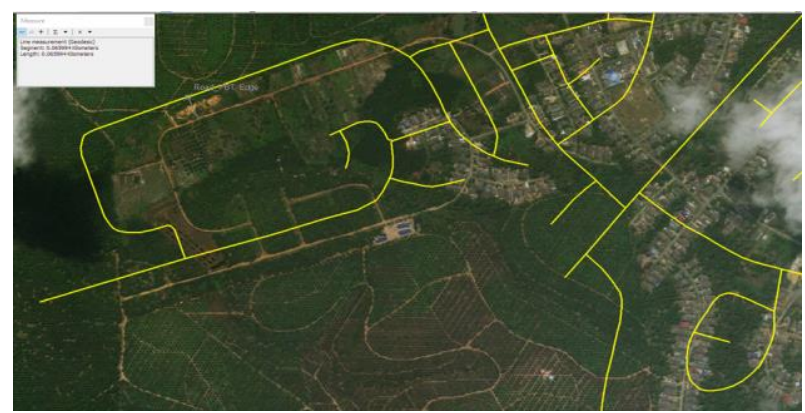

Figure 2: A "shifted" road network from original dataset
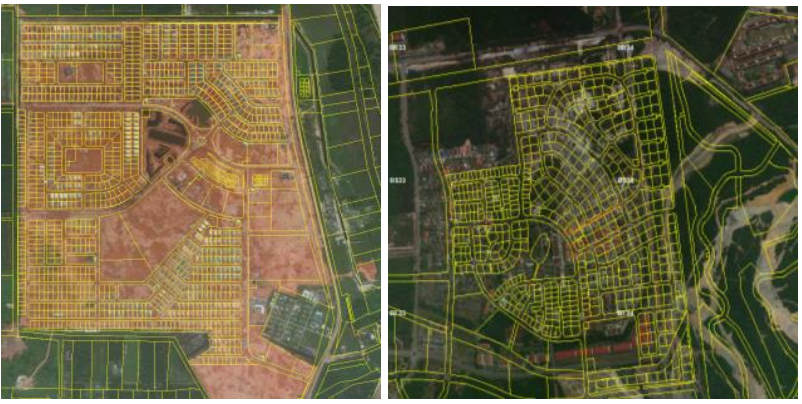

Figure 3: Example of correctly assigned (left) and slightly moved (right) land parcels based on satellite imagery validation

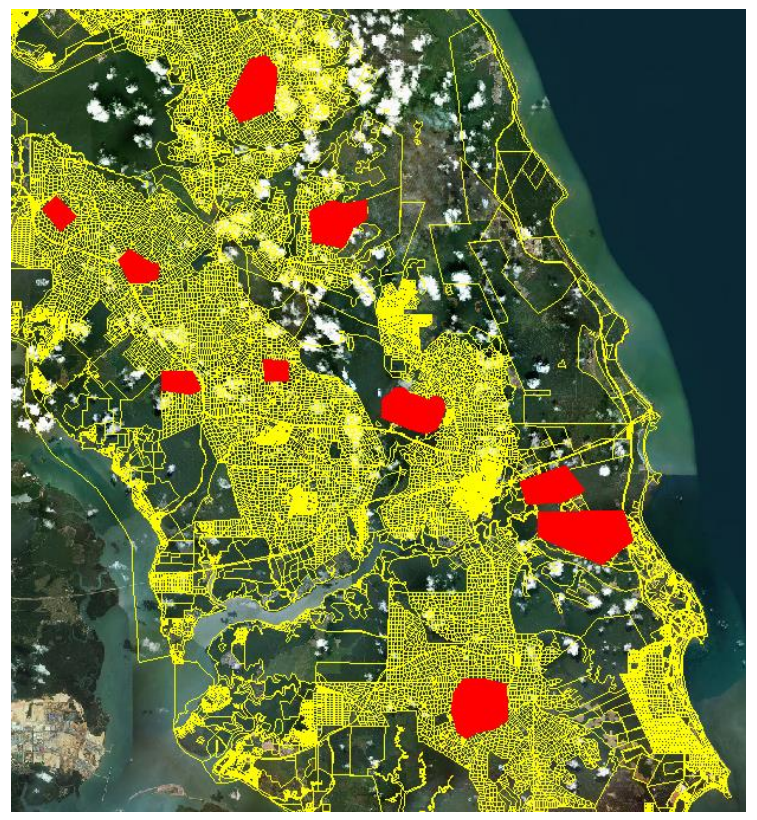

Figure 4: Some geometrical corrections required (red polygon) for land parcel layer

Comparison between available data with difference sources also conducted to produce a new up-to-date and completed layer with good quality control. Example for road network, some part of OSM (Open Street Map) data is not completed (refer to Figure 5) and will be updated using the provided data or manually digitizing the road based on base-map imagery (e.g. estate unpaved road).

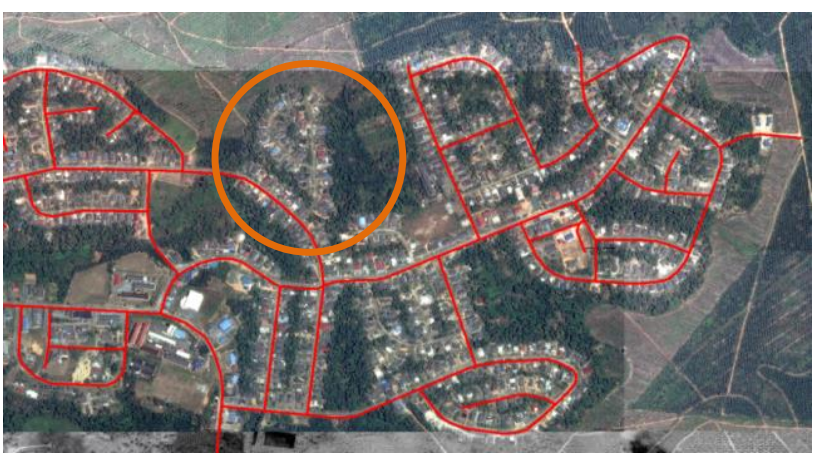

Figure 5: Example of correct road alignments from Open Street Map (OSM) but with missing data (orange circle)

\subsection{Base-map Preparation}

GIS data ready is a concept to synchronize all datasets from different sources, types, accuracies, formats and projections into a single database for better management (e.g. update) and minimizing some errors (e.g. data redundancy) as reported by Gago-Silva (2016). This method is very crucial and should have a general, high quality and accuracy base-map to begin with. In this project, we proposed a few satellite imagery based-maps with the following characteristics:

- Latest available imagery

- $\quad$ Free and open extract / download

- Good quality (less cloud cover), and

- $\quad$ Based on grid and tiles

Approximately 3000 grids (Figure 6 and 7) for Pengerang area with 1-kilometer camera height using Google Earth software. The overall processes for base-map preparation include the following procedures:

- Screen download and georeference the image to the actual coordinates.

- Match the existing data/layers with the base-map

- Digitize unavailable data on-top of the base-map.

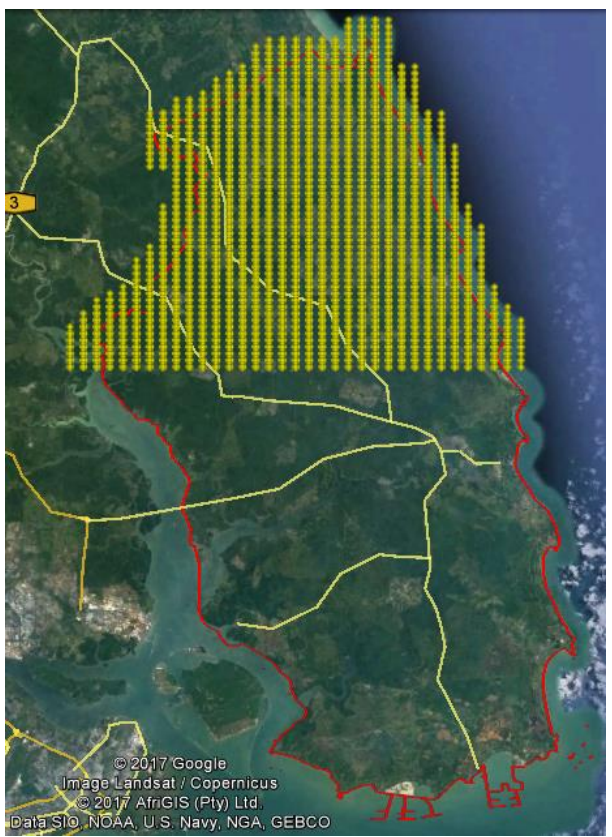

Figure 6: Example of grid and tiles for updating of the basemap 


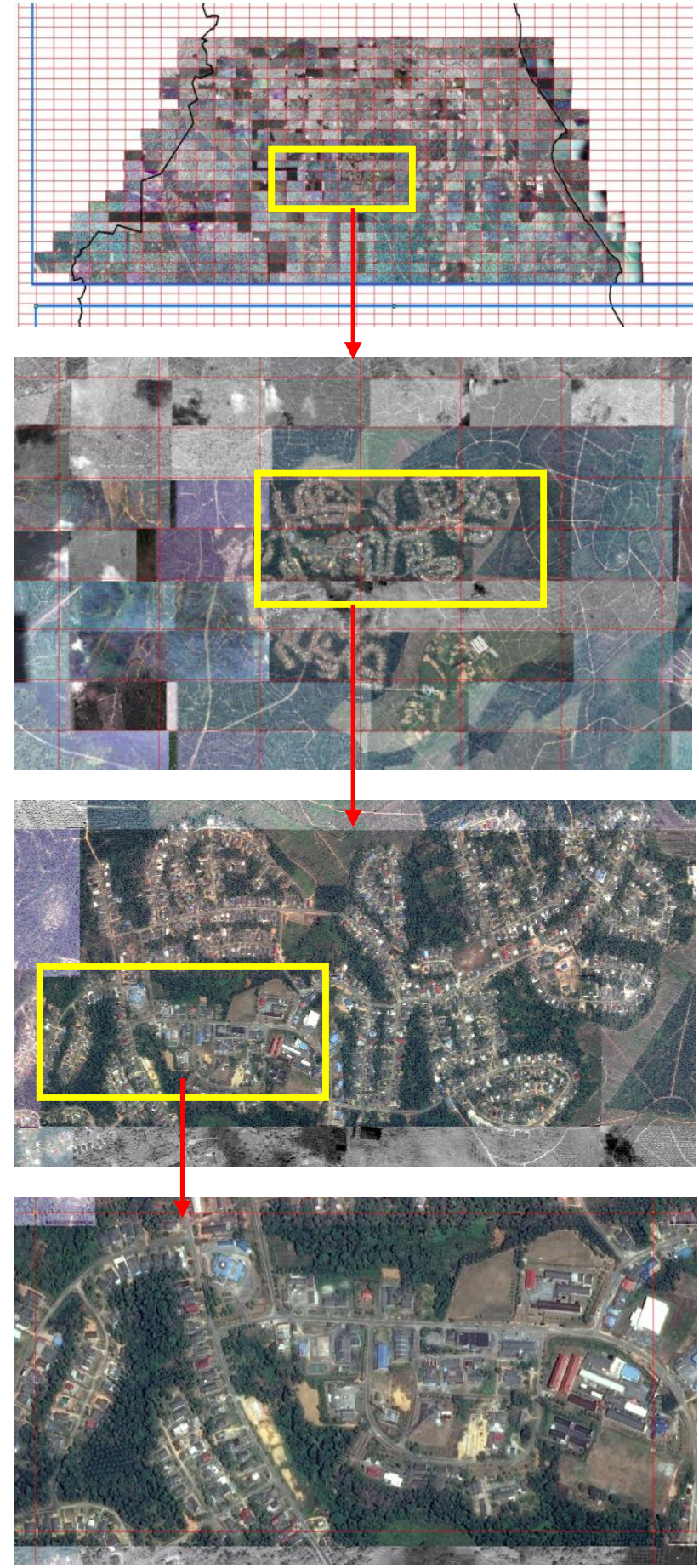

Figure 7: Example of grid/tiles and level of zoom details

The main purpose/benefit using grids/tiles approach in basemap imagery preparation is to make the updating the imagery/area easier. For instance, simply capture the imagery of same (for the following year) once it released by Google Earth. New emerging technology such as Unmanned Aerial Vehicle (UAV) also able to update the imagery at a particular grid (on request), especially in monitoring development progress/planning purposes, etc.

\section{SYSTEM DEVELOPMENT}

\subsection{System Architecture \& User Interface}

Pengerang Disaster Management System (PDMS) highlights the importance of emergency mutual aid - similar to PAGEMA (Pasir Gudang Emergency Mutual Aid) system which was developed by the Pasir Gudang Local Authority. The PAGEMA system has no GIS component. The PDMS system focuses on environmental aspect related to disaster/hazard emergency preparation. The purpose is to assemble various parties from government agencies to high risk industries for contributing efforts in managing emergency within PBT Pengerang jurisdiction. The proposed system meant for distributing disaster information - one stop centre (status, manpower and assets) to other participating stakeholders such as police, health centre, fire and rescue, volunteers and others.

The operation is based on voluntary basis to assist in protecting the public from injuries and health hazards, preventing losses and damages to property, safeguard the environment and working with other contingency plans including the agencies at State/Province level (e.g. Tier 2 level) or at the National level (e.g. Tier 3 level). The system will act as the intelligent centre and operation for Wakaf Brigade (PBT personnel volunteers) for their operation planning purposes. Figure 8 shows the system architecture for PDMS.

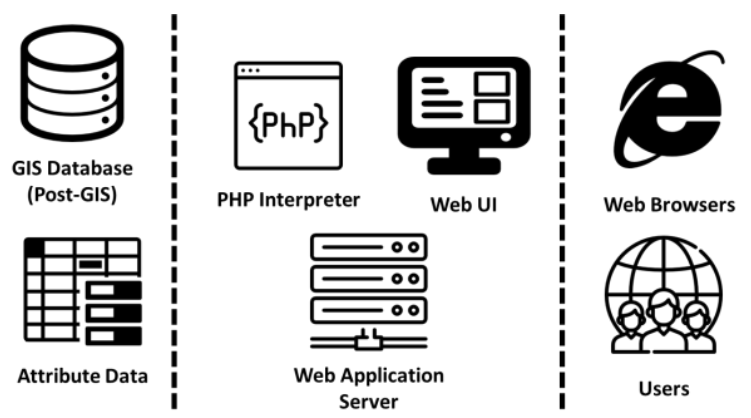

Figure 8: System Architecture for PDMS

The system architecture contains two major components; frontend and back-end. Front-end covers Web User Interface, Web Browser and Users, meanwhile back-end covers Web Application Server, PHP interpreter and GIS database. The system will take the input from users and continuously display (result and analysis) to enable the management of decision making of the real situation.

The system can be accessed by separate logins for administrator and user. The administrator has the rights to control the level of accessibility for every user, so that users from different departments cannot access the data which they are not authorised to. Figure 9 shows the user interface for the login.

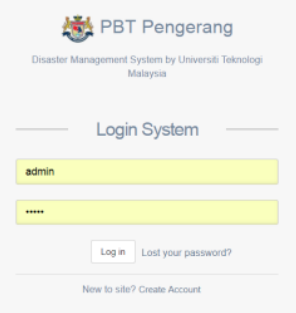

Figure 9: User interface (UI) to login the system 
Meanwhile, Figure 10 shows the main UI after logged in. The UI was designed with the focus on maximizing usability and the user experience. Leaflet was utilized as spatial component to provide interactive maps at the front-end, while Web Map Service (WMS) was implemented at the back-end to provide comprehensive GIS-based analysis and services such as server based information query and spatial processing.

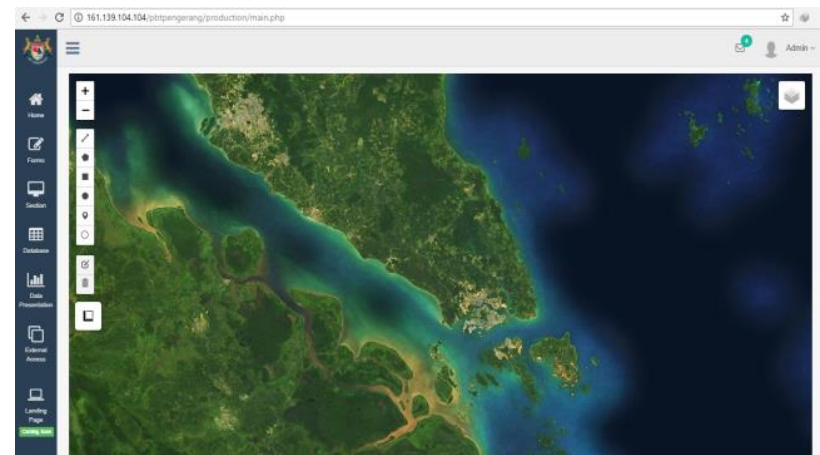

Figure 10: The PDMS GUI

\subsection{GIS Database Server}

GIS database server is designed and developed with the emphasize of creating a centralized system - sharing GIS resources with stakeholders during disaster incident. Key objectives include reducing data duplication; improving the data integrity and concurrency, and accuracy of information used in decision-making while increasing the data reliability. Initially, the database system has the following recommendations:

a) A centralized GIS database server supported by open source implementation (PostgreSQL and PostGIS).

b) Open source GIS software - Quantum GIS (QGIS) for desktop spatial data administration and editing.

c) Centralized services among users and departments.

There are three groups of database tables (Group A, Group B, Group C) in representing base-map, PDMS Stakeholders, and unit from Jabatan Keselamatan Industri dan Kesejahteraan Rakyat respectively. For example, group A consists of basemap layers such as road network, satellite imagery, water bodies, Mukim boundary (District), land parcel, point of interest (POI) and others as shown in Figure 11.

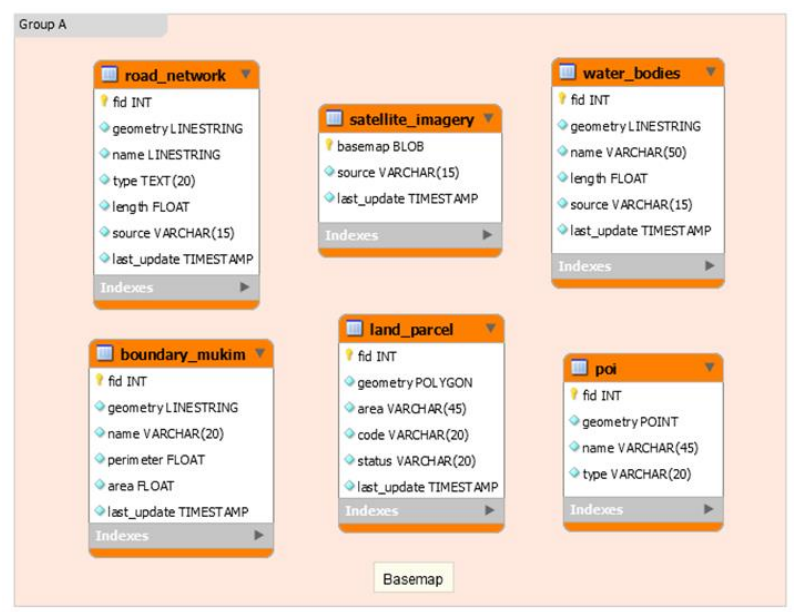

Figure 11: Database tables consist of base-map and POIs.

There are four types of geodatabase user permission and roles implemented in the database development, they are data viewer, data editor, data creator and data admin. Data viewer only allows its users to view (data layers) with limited usage.
Meanwhile data editor allows its users to view, edit and update the data. The data creator role allows its users to create new data (features and layers) in the database, whereas the data admin (known as superuser @ root) have the capabilities of all users.

\subsection{Map Service and Analysis}

Map service allows external hosting of spatial data source from agency such as PBT Pengerang. Spatial data can be stored at stakeholder's local physical storage, while allowing File Transfer Protocol (FTP) accessible folder to grant access for map service to publish it over the Web. Various stakeholders able to publish their layers via web map publisher then enable FTP accessible to publish it over the Web.

In general, the map service offers map viewing capability, basic map functionalities (e.g. zoom, identify, panning, buffering) of the published layers. The map service could be accessed publicly. At the moment, the service deals with the following layers:
a) Mukim/District (boundary)
b) River and road (network)
c) Parcel Lot (land)

Database with geometry and attribute information, is published via Map Publisher Service, to static file (Shapefile). The publishing service will let user to publish the files to a folder that is accessible by FTP. Map service that is hosted externally, will show the published layers at client side. The layers for PDMS supposed to be defined before final publishing.

By implementing Web Map Tile Service (WMTS) standard, query process is formulated based on bounding box and map type. Map type defines as planar or spherical, which implies a planar map or geocentric map. While querying a layer, several information should be sent in the request URL. A layer identifier should be indicated, the web service versioning, the bounding box, the projection as well as the map type. The map service will then retrieve relevant layers and return in a tiled image with the vector layer being rasterized.

Spatial data comes in many varieties and it is not easy to arrive at a system of classification that is simultaneously exclusive, exhaustive, imaginative, and satisfying. (Upton and Fingelton, 1985).

Figure 12 shows the spatial data overlay with on-click information query. Overlay is a GIS operation that superimposes multiple data sets (representing different themes) together for the purpose of identifying relationships between them. External data (authority boundary information) is overlaid with online based map (MapBox) to provide supportive spatial information (location). GIS provides an environment where location is linked with tabular data, thus easy for users to identify each feature to get the attribute information (on-click). 


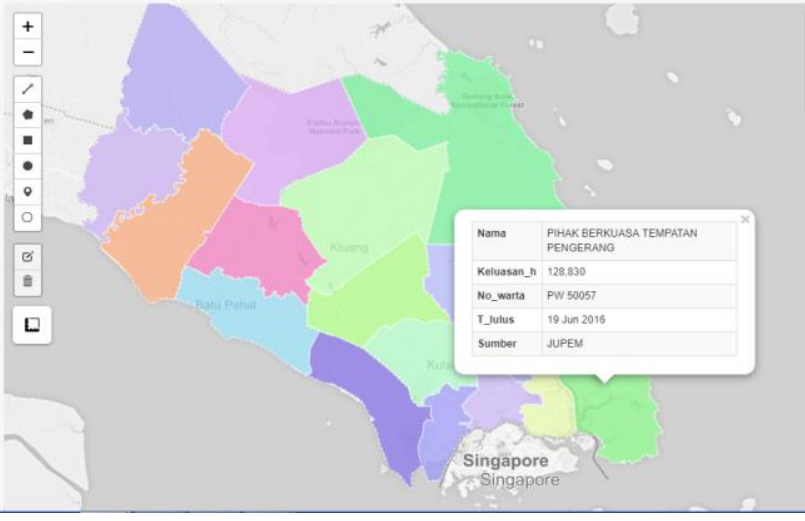

Figure 12: Spatial data overlay with on-click information query.

Meanwhile, Figure 13 shows multiple vector overlay (river and road) on top of online satellite imagery. This process allows users to use their own datasets to provide extra information which cannot be obtained solely from based map. Road network information is very vital for disaster management which can be used in evacuation planning.

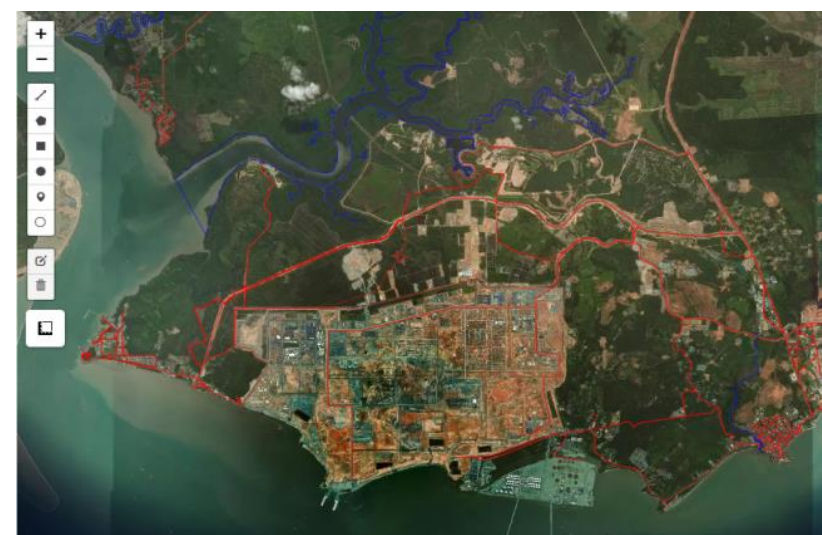

Figure 13: Multiple vector overlay (river and road) on top of online satellite imagery.

In Web GIS application, measurement tool is important to calculate an area, length and perimeter on specific location or places. The PDMS was supplied with this feature to provide capability to measure any related incident to disaster and emergency responds. Figure 14 shows a measured area of 2,385 hectares in the RAPID Pengerang. RAPID is a term used for Refinery and Petrochemical Integrated Development.

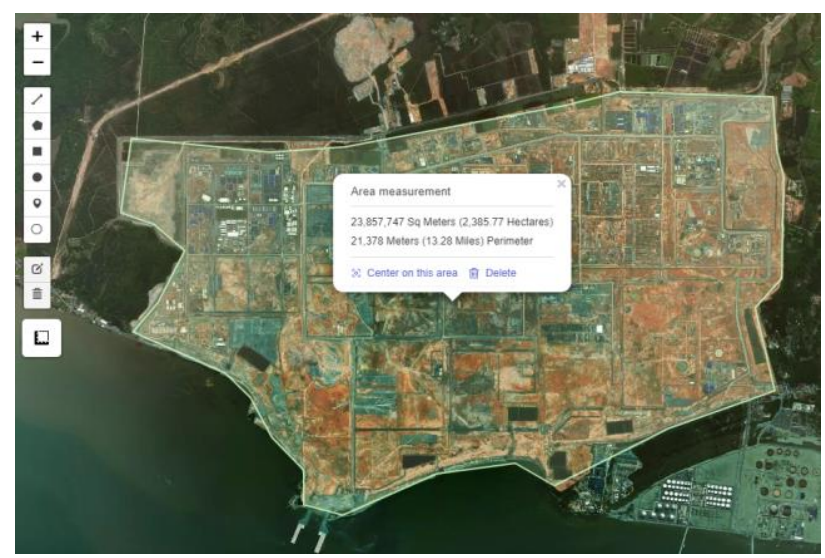

Figure 14: A measured area of 2,385 hectares in the RAPID Pengerang.
The PDMS also implemented network analysis as one of its analysis components. The short route or the route of least impedance between two or more points, taking into account connectivity and travel restrictions such as one-way streets and rush-hour traffic. Figure 15 shows the routing analysis from location A to location B with details such as distance length $(6.2 \mathrm{~km})$, time taken $(15 \mathrm{~min})$, and roads junction involved. This network analysis is important for emergency response which advises the road users for the best (shortest) route in order to save time or any instances.

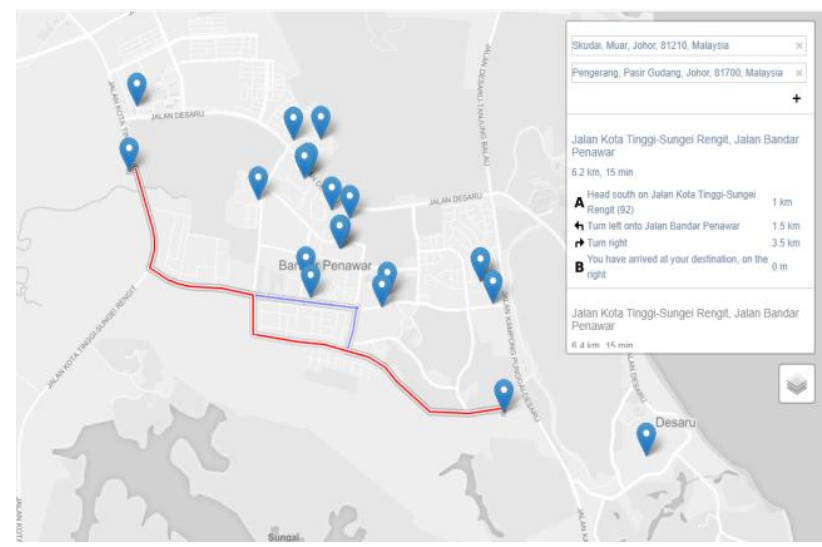

Figure 15: Routing analysis from location A to location B with details such as distance length $(6.2 \mathrm{~km})$, time taken $(15 \mathrm{~min})$, and roads junction involved.

Moreover, a spatial query (buffer) is a query that returns features based on their spatial relationship with query geometry was implemented in the PDMS. The purpose is to identify nearby POI around a location. For example, Figure 16 shows a buffer analysis radius of $2 \mathrm{~km}$ near Penawar Town, in Pengerang. This analysis identifies any POIs that intersect within the $2 \mathrm{~km}$ of the buffer area. In an emergency response, it is important to search places (e.g. hospital or facilities) that closest or nearby to the incident location.

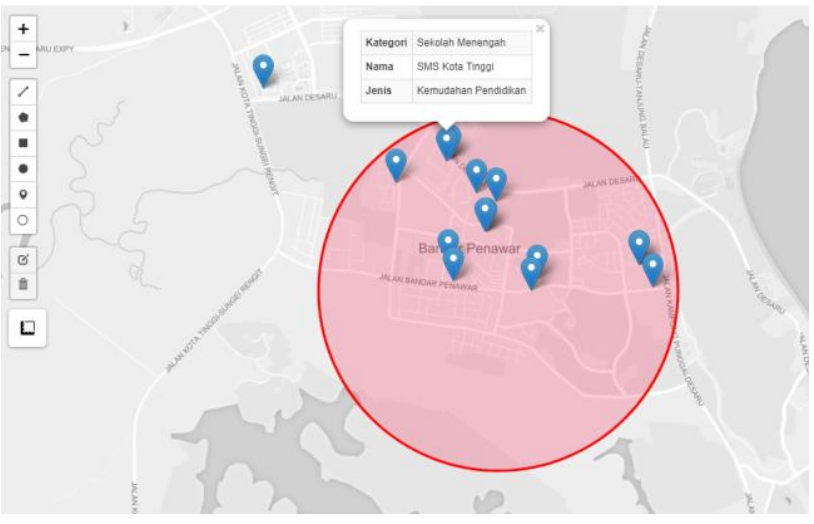

Figure 16: Buffer analysis radius of $2 \mathrm{~km}$ at near Penawar Town, at Pengerang.

Spatial information is being retrieved by event e.g. A serverside request for a certain layer. Based on current architecture, a client-side is tasked to retrieve appropriate server-side layers from multiple sources. Layers such as cadastre, natural features, point of interests, emergency response and etc, was retrieved from server side, identified by client side.

Currently, the client side can choose which layer to retrieve for spatial information. On the other hand, buffering is done via selection of certain layers to be buffered through web service request. Below is example of the query: 
http://demoserver.com/?wms\&REQUEST=BUFFER\&LAYER S=RIVER_PBT,LOT_PBT,POI_PBT,ER_PBT\&MAP_TYPE= SPH\&BUFFERLOCATION=XXXX,XXXX\&BUFFERSIZE $=$ $\mathrm{XX}$

The return response of the above request will be in layers with naming started with "buf_" for each buffered layer, e.g. River_PBT buffered layer will be named as buf_River_PBT etc. Buffered layer will be returned as a collection of the layers in each designated tiled layer.

\section{CONCLUSION}

We have described spatial datasets for the PDMS with few enhancements to the data. Geospatial database was developed with recommended approaches such as user authentication levels, open source architecture and sharing with internal/external stakeholders. The developed system able to share geospatial data/layers via web services, perform analysis such as query (data retrieval) and buffering on the server side (online).

We anticipate the system could be enhanced with real time disaster information modelling such as assets tracking (via GPS receiver) of the rescue teams or vehicles. Other important features for improvement such as environment and weatherbased parameters (wind direction, rain forecasting) for real-time modelling.

\section{REFERENCES}

Dubayah, R.O., Swatantran, A., Huang, W., Duncanson, L., Tang, H.,Johnson, K.,Dunne, J.O., and Hurtt, G.C., 2017. CMS: LiDAR-derived Biomass, Canopy Height and Cover, Sonoma County, California, 2013. ORNL DAAC, Oak Ridge, Tennessee, USA https://doi.org/10.3334/ORNLDAAC/1523

Gago-Silva, A., 2016. GRASS GIS in Grid Environment. Figshare https://doi.org/10.6084/m9.figshare.3188950

NaDMA, 2017. Current Status of GIS-based Disaster Management. Proceedings of International Conference on Geomatics and Geospatial Technology (GGT 2017). Kuala Lumpur, Malaysia.

Razak., K.A, 2017. National Disaster Management Framework Challenges. Invited Presentation. Proceedings of International Conference on Geomatics and Geospatial Technology (GGT 2017). Kuala Lumpur, Malaysia.

Upton, Graham J. and B. Fingelton, 1985. Spatial Data Analysis by Example Volume 1: Point Pattern and Quantitative Data John Wiley \& Sons, New York. 